\title{
Grandparents of Autistic Children - The Best Support System
}

\author{
Elona Mano \\ PhD. candidate Europian University of Tirana, Albania \\ kristinamano@yahoo.com
}

\begin{abstract}
There is an increase of cases with autism spectrum disorder each year. The truth is that tens of thousands parents face a tremendous phase when they understand what autism is. Autism and autistic children are the focus of many studies in the last decades, but the focus is mainly on the children or the parents of these children. What happens with grandparents of autistic children? They suffer twice. They suffer for the grandchild and for their own son or daughter. In addition, maybe they blame themselves for that inherited "bad" gene that caused the disorder. To go further they maybe feel useless because of their age, their conditions or even their missing information. One of the biggest challenges in providing services to people with an autism spectrum disorder is that they need help 24 hours per day. Not only the grandparents, but even all the other members of the family can help a lot. This study is focused on grandparents's point of view. What is autism and what does it mean for them to have an autistic grandchild? During the interviews the participants raised some important issues. To have grandchildren with autism is not easy, but at least grandparents are willing to help anyway. The important is that an autistic child feels the presence of everyone.
\end{abstract}

Keyword: autism, parents, child, grandparent

\section{Introduction}

Autism is a neurodevelopmental disorder characterized by impaired social interaction, communication, and restricted and repetitive behavior. There are a lot of studies on etiology of autism, but the real cause of autism is still unknown. One of the recent studies confirms that autism risks increase with mom's age. Mothers over 40 compared to mothers aged 20-30, have $50 \%$ risk to have autistic children (Kurti, V. 2010). Another big issue is the relation of autism with MMR vaccination. It is believed that mercury, a harmful substance, is present in vaccines that children have to take when they are about 12 months. Another source of this problem seems to be a chromosome. What science has discovered is the presence of fragile $X$ chromosome in autistic children, that is present even in mental retarded people (Powers, D. M. 2000:27). Another source of autism disorder is believed to be the environment pollution (Kurti, V. 2013). Taking in consideration all we said above, it seems that the debate around autism is still a kind of natue-nurture problem.

The spectrum of disorder is wide. It includes: Asperger Syndrome, Classic Autism, Pervasive Developmental Disorder and Rett's syndrome. This means that the severity of the disability is different for different individuals. Studies on brain structure show that there is not one damaged area, but there are some of them. Based on the severity of the disorder and for practical reasons, autistic children belong to cathegories such as: Severe Autism; Mild Autism; Moderate Autism or Low- functioning Autism and High- functioning Autism.

Living in a family with a child with autism disorder is tiresome. It is time consuming and a restless job. It is not only physicaly difficult to be handled, but it gives psychological stress especially when the family is given the diagnosis of their child or grandchild (Powers, D. M. 2000:45). The tremendous truth is a shock not only for the parents of the child, but even for siblings, grandparents and all the relatives. 


\section{Grandparents as part of ecological context}

Social ecological context was pioneered by Bronfenbrenner in 1979, who suggests that the ecological system comprises a number of subsystems: the microsystem, mesosystem, exosystem and macrosystem. Every person lives in a microsystem ( family, friends, teachers, etc) that is inside a mesosystem (interactions between all the factors) which is inside exosystem (social environment that influence on the child). These three systems form a macrosystem. (law, society, values, etc) (Woolfolk, 2010, 66).

The microsystem is the nearest environment where a child can experience different emotion in interaction with his parents, grandparents, other children or teachers. This relation is two directional. What happen to the child has impact on the parents and what happens to the parents is felt even by the child. Mesosystem has to do with interaction of all the actors of microsystem. Ekzosystem includes interaction between two or more environments such as friends and neighbours, madical care, extended family, peers outside the school, other parents, support groups, and local community. Even psychologists or experts of the field are an important part of this system. The child is not directly connected with this system but it has an impact upon the child, for example the mass media can describe disabled people as people in need or undesirable. Based on child's disorder neighbours can be humanist and friendly or stigmatizing. The impact that economic and political factors have on the child has to do with macrosystem. Macrosystem is the society expressed in values, laws, conventions, traditions and have impact upon families. The bioecologic system of a child can be expressed as: the child is influenced by microsystem of his mother, father, brothers, friends, teacher, by mesosystem of interaction between these people and by eksosystem of governmental policies. (Woolfolk, 2010, 67).

As part of a microsystem, grandparents are the immediate context where the child spend a lot of time. As a part of the family they hear, feel and try to do their best. But, autism is too difficult to be understood by many people, because there is not just one autism, there are a lot of forms of autism. Grandparents of today are more active and have a lot of forms to be informed compared to other generations, but they still have their own ideas, culture and prejudices. Maybe in different countries they are better informed, guided and organized, for example, in USA today there are a lot of facilities for grandparents of autistic children. One of them is grandparents' network where they can share opinions and help each other, not only for their autistic grandchildren, but mainly to help their own children (parents of the autistic child). On the other hand there are countries where grandparents have never seen a computer or even don't know what it is. But what still remains the same is the unconditioned love and sacrifice that grandparents want to do just to help their family.

(Attar-Schwartz et al., 2009, 74 ) admits the influence of grandparents on the well-being of their grandchildren in different family types:

"Public institutions ...need to recognize grandparents as a potentially important role source for support in adolescents" lives in general, but in particular, for those increasing numbers of adolescents going through a family transition. "

Even though there are not a lot of studies concerning the influence of grandparents in their autistic grandchildren and his family, their role is indispensable. Eventhough the truth about autism is so sad, grandparents should be told about it. The best think to do is to have an open and warmheart talking about their grandchildren. Nothing can change what a grandparent feels about his grandchildren. Whatever happens grandparents are"programmed" to love the grandchildren the same, or even more (Powers, D. M. 2000:53). Baranowsky 1990 found that it doesn't mater the distance between a grandparent and a family with a child with a disorder. What matters is that they find the way to stay in touch. Even when the grandparents were in poor health conditions they gave the best of themselves, because for them "the getting is in the giving". Globalism has brought a lot of changes even in the nucle of the family. The enormous rate of divorces, the different addictions the individuals have, or the economic crisis have made grandparents the first choice for grandchildren normal life and wellbeing. In cases of children with disabilities the involvement of grandparents is indispensable. Eventhough they suffer twice, they love twice and they give all they have to give.

\section{Method}

The sample for the current study includes grandmothers, of autistic children diagnosed with Autism Spectrum Disorder (Asperger's Disorder, Autistic Disorder, Rett's syndrome, Childhood Disintegrative Disorder, Pervasive Developmental 
Disorder, not otherwise specified) based on DSM-IV-TR (Diagnostic and Statistical Manual of Mental Disabilities). Parents are members of MEDPAK (Protect the Rights of Parents of Persons with Disabilities), a non-governmental organisation.

There were a focus group conducted with grandmothers of autistic children. Five of grandmothers lived in the same house with their grandchildren, four of them lived far away. The moderator gave an overview of the topic, made them sure that everyone point of view would be appreciated. They were made aware they were free to withdraw from the study at any time for any reason. After the moderator created a warm and friendly environment, confidentiality was ensured to all participants.

During the analysis process it was used the textual analysis, which includes a wide variety of things that can be analysed. The process of qualitative analysis aims to bring meaning to a situation rather than the search for truth focused on by quantitative research. In order to minimize the potential bias introduced in analysing and interpreting interviews data, Krueger \& Casey (2000) point out that the analysis should be systematic, sequential, verifiable, and continuous.

The first step was indexing and charting as a form to manage the data. It was used a computer-based approach for cutting, pasting, sorting, arranging and rearranging data through comparing and contrasting the relevant information. It was numbered each line of each transcript and two hard copies of each transcript were made; one to cut up and one that stays intact for later reference. This arrangement helped the moderator to be alert to changes that maybe occurring from one person to another. At the end it was written on each page one of the questions to be analyzed. The author cut out relevant quotes and taped them to the appropriate place on the large sheet of paper. The quality of quotes varied. The unused quotes were left aside for later consideration. At the end of this process an overview was prepared integrating paragraph that described responses to that question. When this was finished, the author went to the next question, and so on.

For interpretation of coded data Krueger (1994) provides seven established criteria: words; context; internal consistency; frequency and extensiveness of comments; specificity of comments; intensity of comments; big ideas. First of all the moderator thought about the actual words used by the participants and the meanings of those words. The author needed to determine the degree of similarity between the responses. Later the analyst examined the context by finding the stimulus that triggered participants responses and interpreted the comment in light of the environment. Sometimes there was a shift in opinion and in order to discover the internal consistency, the researcher traced the flow of the conversation. The frequency relates to consideration of how often a comment is made. There were topics of special interest to participants. The conversation was not video- taped so the intensity was difficult to be spotted. Intensity is communicated by the voice tone, speed or emphases on different words. Based on specificity, responses that were specific and based on the first person experiences were given greater attention. Another thing to be considered by the author was 'big ideas'. Krueger (1994) suggests taking a break for sometime at this stage in order to refocus on the big picture.

When grandmothers were asked about the way they help, they gave the following information.

"I live in the same house with my son and his family, when my grandson was a little boy, I followed him verywhere, but now I can't do it anymore. I just can't. I do some chores and that is all. " Grandmother one

"When my daughter cries I try to calm her. I pray every day, God knows what happened to our son and he will help him to recover" grandmother two

"... I take care for the other grandchild, the brother of Tom. My doughter in law is so busy taking care of Tom."

Grandmother seven

Grandmothers are not clear about their grandchildren disorder.

"It doesn't matter what it is. He is not fine, that's all" Grandmother eight

"Sometimes my nice gives me information about it, but is complicated. I love my nephew so much. I would die to make him better. "Grandmother three 
"None gave me explanations at the begining, but now I know something and I try to give my best. I do it for my son. I do it for my family. "Grandmother five

"I have never interfered. I don 't ask them too. Its better. I don't want them to feel bad" another grandmother

About the etiology of autism they gave different opinions. It seems that they have informal information. No specialist has given them a proper explanation.

"Is difficult. They don't know what happened, but a doctor said me its vaccination. If only we hadn't done it."

\section{Grandmother five}

"In my family there are no people like this, I wonder what happened. Maybe during the delivery something happened. I don't know. "Grandmother four

"My daughter-in-law did a lot of ultrasound when she was pregnant, but she smokes too. " Another grandmother

"When he was 4 month old, he fall and hurt himself. Maybe something happened. Who knows."

\section{Conclusion}

This study aimed to understand the grandparents's point of view concerning their attitude on autism. Having an autistic child is a burden not a parent or grandparent can hold, especially when the diagnosis is low functioning autism. Eventhough the science is focusing on autistic children, about the factors that cause autism, or their school integration, or the parents, another issue remains the support given by the immediate environment to which the child has contact, that is grandparents. Grandparents may see the reality in a different way. It is our duty to understand, support and try to help them in anyway. At least, we should explain them how to help their grandchildren. Eventhough they have a lot of issues to ask, they have a lot of love to give. Parents of autistic children around the world seem to be suspicious about society and services, but they trust their parents endlessly. If grandparents are informed properly, they will be more effective in everything.

\section{References}

Attar-Schwartz, Sh., Buchnan, A., Griggs, J., Tan, J., Flouri, E. (2009). Grandparenting and Adolescent Adjustment in TwoParent Biological, Lone-Parent, and Step -Families. Journal of Family Psychology,23,67-75

Baranowski, M. D. (1990). The grandfather-grandchild relationship: Meaning and exchange. Family Perspective, 24, 201 215.

Powers, M. 2000. Femijet me autize. Ilar. Tirane

Krueger RA \& Casey MA (2000) Focus Groups: A Practical Guide for Applied Research, 3rd ed. Thousand Oaks, CA: SAGE Publication

Krueger RA (1994) Focus Groups: A Practical Guide for Applied Research. Thousand Oaks, CA: Sage Publications.

Kurti, V. 2013. Autizmin e mësova nga ju. ADA. Tiranë

Kurti, V. 2010. Autism. ADA. Tirane

Woolfolk, A. (2010), Psikologji Edukimi, Qëndra për arsim demokratik. Tiranë. p,66-68. 